Research Article

\title{
Association of problematic mobile phone use with psychological distress and self-esteem among college students in South India: a cross-sectional study
}

\author{
Prachi Pundir*, Teddy Andrews, Binu V. S., Ramachandra Kamath
}

Department of Public Health, Manipal University, Manipal, Karnataka, India

Received: 05 August 2016

Accepted: 01 September 2016

*Correspondence:

Dr. Prachi Pundir,

E-mail: prachipundir2012@gmail.com

Copyright: ( ) the author(s), publisher and licensee Medip Academy. This is an open-access article distributed under the terms of the Creative Commons Attribution Non-Commercial License, which permits unrestricted non-commercial use, distribution, and reproduction in any medium, provided the original work is properly cited.

\begin{abstract}
Background: Mobile phones have penetrated into the lives of common man to the extent of becoming one of the basic necessities for surviving in this modern world. Apart from the health effects of radiation from handsets, concerns have been raised over the behavioural effect of using mobile phones, especially among younger generation. Problematic mobile phones use (PMU) may be considered an addiction-like behaviour related to an individual's mobile phone use.

Methods: A study was conducted among 1108 college students in the age group of 18-25 years to find the prevalence of PMU using a uni-dimensional problematic mobile phone use scale (PMUS) developed by the authors. The prevalence of PMU among the college students was $26.8 \%$ and it was related with psychological distress and other predictor variables using statistical analysis.

Results: Psychological distress was present among 5.8\% and lower self-esteem using was present among $13.2 \%$ of the participants. The mean score of GHQ among problematic mobile phone users was $10.14( \pm 4.87)$ whereas the score among Normal users was $7.85( \pm 3.42)$. A significant cross-sectional association was found in between problematic mobile phone use and psychological distress, lower self-esteem, gender, smartphone use, multiple chatting applications, committed relationship status, relationship with mother and frequency of mobile phone use.

Conclusions: Health education is required for increasing awareness about PMU among the college students. Further research should be undertaken and factors related to PMU may be considered for intervention.
\end{abstract}

Keywords: Problematic mobile phone use, College students, Psychological distress, Self esteem

\section{INTRODUCTION}

Since the introduction of wireless technology in India in 1995, there has been a sea change in Indian telecommunication. ${ }^{1}$ The last decade has seen an explosive rise in the number of mobile phones being used by the common people. According to the data revealed by Telecom regulatory authority of India in March 2014, there were 904 million mobile subscribers with a teledensity of 72.94 percent. $^{2}$ The primary function of mobile phones is to connect people, but it is being positively used in other areas such as healthcare, finance, education and agriculture. ${ }^{3}$ It is a driving force of economic development and increasing connectedness. ${ }^{4,5}$

From replacing wrist watches to tape recorders and cameras, mobile phones have evolved as multi-utility devices and have provided ease of access for its users. Although there are numerous benefits to this technology, it is not risk-free. Besides the radiation (Electro Magnetic Fields) produced by the mobile phones, there is a rising concern over the behavioural effect and problematic use 
of mobile phones. ${ }^{6}$ Although internet addiction (contents' page) and pathologic gambling are included in the DSM$\mathrm{V}^{7}$, Problematic use of mobile phones (PMU) is not defined in the substance-abuse category (non-substance related). ${ }^{8}$

The problematic use of mobile phones is conceptually vague term; it has been related to different facets such as excessive, prohibited, financial, dangerous use and dependence on the mobile phones. ${ }^{9,10}$ Also, it has been linked to impulsivity, urgency, sleep disturbances, psychological distress, low self-esteem, depression, anxiety and other behavioural aspects in adolescents and young adults in various research studies across the world. ${ }^{11-21}$

The mobile phone industry focuses on young people as its highest consumers; technology being attractive and useful for them in the context of the 'connected' mindset. Mobile phone use is excessively common among this age group and it may affect their behaviour or cause a negative impact on their subtle minds. Compared to the extent of mobile phone usage in India, there is minimal research related to the problematic use of mobile phones and its effects on mental health status of the users. The study aims to determine the prevalence of problematic mobile phone use among the college students, to identify associated factors and the relation with psychological distress and lowered self-esteem among students.

\section{METHODS}

The cross sectional study was carried out in ten degree colleges of Udupi taluk during the period of February to April, 2014. The participants were undergraduate students in the age group of 18 to 25 years belonging to courses of various streams such as commerce, computer application, business management, science, arts. A segregated analysis for different streams was not done.

The inclusion criteria were the age category for young adults 18-25 years and owning a mobile phone and using it at the time of study.

The sample size was calculated for prevalence of problematic mobile phone use as $15.4 \%$ from the pilot study, and for $95 \%$ confidence level and $20 \%$ relative precision of the estimate. A cluster effect of two and $10 \%$ oversampling was done to account for non-response after which the sample size came up to 1103 responses.

Two stage cluster sampling was used to select the respondents. At the first stage, 10 colleges were randomly selected by lottery method from a list of 21 coeducational degree colleges in Udupi taluk and permission was obtained. At the second stage, classes which were free during visit were selected conveniently and questionnaires were administered to all students in a class irrespective of mobile phone use. A fixed minimum number of students from each of the ten colleges were taken by dividing the sample size by number of colleges.

\section{Data collection method}

The questionnaires were distributed to participants in classroom settings at a predetermined time in the presence of principal investigator. Questionnaires were bilingual (English and local language), self-administered and anonymous. Instructions were given before commencement and informed consent was obtained from all participants.

Teachers were requested to leave the classroom during the 25-30 minute period to avoid any influence, bias or doubtfulness. After data collection, the questionnaires of respondents not fulfilling the inclusion criteria were eliminated and not considered for the analysis. A total of 1219 questionnaires were distributed and collected out of which 83 were eliminated because of no mobile use or incomplete questionnaires and 28 questionnaires were eliminated because of patterns followed in filling the selfadministered scales. A final 1108 responses were considered for analysis

The questionnaire contained six sections: 1. Sociodemographic details 2.Mobile phone use patterns and information on calls and messages 3. Personal characteristics and relationships of the participant 4 . General Health Questionnaire (GHQ)- 12 item 5. Rosenberg's self-esteem scale (RSES) 6. Problematic mobile phone use scale (PMUS).

\section{Variables and measurement scales}

\section{Measure of problematic mobile phone use: problematic mobile phone use scale (PMUS)}

PMU is defined as a person's perceived tendency to chronically use mobile phone and its services in excess of needs and an uncontrolled manner, resulting in behavioral symptoms and a negative social outcome, to the extent of causing an impact on daily living. A uni-dimensional tool was developed by the researchers to assess problematic mobile phone use among the participants.

The rationale behind developing a scale for problematic mobile phone use was that none of the scales for problematic use of mobile phone have been validated among rural and urban young adults in India.

The 16-item PMUS was developed after a thorough literature review considering various behavioural problems that a problematic mobile user may exhibit such as dependence, dangerous use, excessive use, sleep disturbances, ringxiety, behavioural problems etc. The scale was rated from 1-4: hardly ever, sometimes, often, and always. Item 4 was reverse coded. The score $<35$ suggested normal use, score in the range 35-48 suggested 
moderate problematic use and score $>48$ suggested high problematic mobile phone use.

\section{Tool development and validation}

35 questions related to problematic use of mobile phone were listed after literature review. The questions having almost the same meaning and expected to capture the same kind of behaviour were condensed to form a single item.

The interim scale was formed with 20 questions scored on likert 1 to 4 i.e. hardly ever to Always. The interim scale was given to psychiatry, psychology, communication experts and mobile phone users (young adults) for content validity. Consequently, some questions were changed, added or eliminated which brought down the number of items to 16 .

Each of the 16 items of the scale was weighed on a scale of very relevant to irrelevant by an online survey which reflected that all the 16 items had almost equal relevance, except one item which had low relevance (the item was not removed). The scoring cut-off was decided based on expert suggestion. A pilot study was conducted among 91 participants in which the questions were well understood and answered and a prevalence of $15.4 \%$ of PMU was obtained.

Reliability and validity of the PMUS: A test of internal reliability (Cronbach's alpha) was calculated for the scale which was 0.81 (good) showing the homogeneity of the items. The PMUS was not validated against a standard questionnaire.

\section{Frequency of mobile phone use}

Frequency of mobile phone use was classified as low, medium and high frequency by merging the number of calls and Short Messaging Service categories. ${ }^{12}$ SMS are synonymous with other messages: (including that from messengers) in this study.

The categories were based on the frequency of calls and SMS messages received and sent in one day, during the past 30 days. Frequency of calls and messages 0 per day: low, 1-5 per day: low, 6-10 per day: Medium, 11-20 per day: High, >20 per day: high.

Thereafter, frequency of mobile phone use was calculated as: Low calls+ Low SMS: Low, Low calls+ Medium SMS or vice versa: Medium, High calls and/or high SMS, or Medium calls+ Medium SMS: High

\section{Family and social relationships of the participant}

Relationship with friends (of same and opposite sex) and family relationships i.e. relationship with father, mother, siblings and relationship between father and mother were analysed based on a five point likert of very good to very poor. The responses very good and good represented a positive relationship while neutral, poor and very poor were categorized into a negative relationship. ${ }^{23}$

\section{General health questionnaire}

GHQ-12 was used as a screening tool for assessing mental health status. The original version of the GHQ is a 60 item multidimensional scale, but a shorter 12-item version is used for assessing psychological distress. ${ }^{27}$ The tool has been used extensively and well-validated in Indian young adult population. Each item is scored on a likert scale of 0-3 in the order of intensity of feelings recently experienced by the participant. Scores from 0-15 suggest normal mental health status, Score $>15$ suggest evidence of distress and Score $>20$ suggest severe psychological distress.

\section{Rosenberg's self-esteem scale}

RSES is a 10-item scale that measures global self-worth by measuring both positive and negative feelings about the self and is considered a reliable and valid quantitative tool for self-esteem assessment. ${ }^{28}$ The likert scale has scoring of $1,2,3,4$ representing strongly disagree to strongly agree; items 2, 5, 6, 8, 9 are reverse scored. Score $<15$ describes low self-esteem, score in the range 15-25 represents Moderate self-esteem and score $>25$ represents High self-esteem.

\section{Data analysis}

The SPSS version 15.0 was used for statistical analysis of the data collected. Socio demographic variables were denoted by frequency tables, prevalence of problematic mobile phone use was denoted by categories and percentages.

The dependant variable was problematic mobile phone use and predictor variables were (a) socio-demographic variables (b) patterns of mobile phone use (c) personal factors (d) relationships of the participants (e) psychological distress (f) self-esteem. The associations between students' problematic mobile phone use and factors were shown by using logistic regression (Odds ratio and $95 \%$ Confidence intervals) by univariate and multivariable analysis. In all calculations, $\mathrm{p}$ values under 0.05 were considered significant.

\section{RESULTS}

\section{Description of the study population}

The socio-demographic characteristics of the participants are shown in Table 1. The mean age of the study population was $19.5( \pm 1.33)$ years. More than half of the participants $(57 \%)$ were in the age category $18-19$ years. $62.0 \%$ of the participants were females. The socioeconomic status was divided into five classes with Class I as the highest income category. ${ }^{26}$ 
Table 1: Socio-demographic characteristics of study sample.

\begin{tabular}{|c|c|}
\hline Variables & n $(\%)$ \\
\hline \multicolumn{2}{|c|}{ Age of participants in years $(n=1107)$} \\
\hline $18-19$ & $632(57.1)$ \\
\hline $20-22$ & $438(39.6)$ \\
\hline $23-25$ & $37(3.3)$ \\
\hline \multicolumn{2}{|l|}{ Gender $(n=1104)$} \\
\hline Male & $418(38.0)$ \\
\hline Female & $685(62.0)$ \\
\hline \multicolumn{2}{|c|}{ Current Relationship status $(n=1104)$} \\
\hline Single & $958(86.8)$ \\
\hline In a relationship & $126(11.4)$ \\
\hline Married & $20(1.8)$ \\
\hline \multicolumn{2}{|l|}{ Current student status } \\
\hline Full time student & $1017(91.8)$ \\
\hline Part time student (Job and study) & $91(8.2)$ \\
\hline \multicolumn{2}{|l|}{ Living arrangement } \\
\hline With parents & $964(87.0)$ \\
\hline With friends/ flatmates & $82(7.4)$ \\
\hline With relatives & $31(2.8)$ \\
\hline Others & $31(2.8)$ \\
\hline \multicolumn{2}{|l|}{ Socio-economic status $(n=1062)$} \\
\hline Class I & $216(20.3)$ \\
\hline Class II & $338(31.8)$ \\
\hline Class III & $268(25.2)$ \\
\hline Class IV & $147(13.8)$ \\
\hline Class V & $93(8.8)$ \\
\hline \multicolumn{2}{|l|}{ Father's Occupation $(n=1042 *)$} \\
\hline Unemployed/ Retired & $27(2.6)$ \\
\hline Unskilled/ Semi-skilled & $107(10.3)$ \\
\hline Skilled & $225(21.6)$ \\
\hline Clerical/ Farming/ Business & $520(49.9)$ \\
\hline Semi-professional & $79(7.6)$ \\
\hline Professional & $11(1.1)$ \\
\hline \multicolumn{2}{|l|}{ Mother's Occupation $(n=1056 \dagger)$} \\
\hline Homemaker & $852(80.7)$ \\
\hline Unskilled/ Semi-skilled & $73(6.9)$ \\
\hline Skilled & $30(2.8)$ \\
\hline Clerical/ Farming/ Business & $59(5.6)$ \\
\hline Semi-professional & $36(3.4)$ \\
\hline
\end{tabular}

* Includes 73 responses with father as deceased; $\dagger$ Includes 6 responses with mother as deceased.

\section{Study of problematic mobile phone use}

Figure 1 shows the prevalence of PMU among college students. According to the definition adopted and scale used, moderate problematic mobile phone users represented $25.7 \%$ whereas high PMU was shown by $1.1 \%$ of the participants.

Majority (65.9\%) of the participants were High frequency users of mobile phone. The median (Q1, Q3) calls and messages among Normal users were 3 (2.5) and 20
(5.50), whereas among problematic mobile phone users were $20(5.50)$ and $80(20,100)$ respectively.

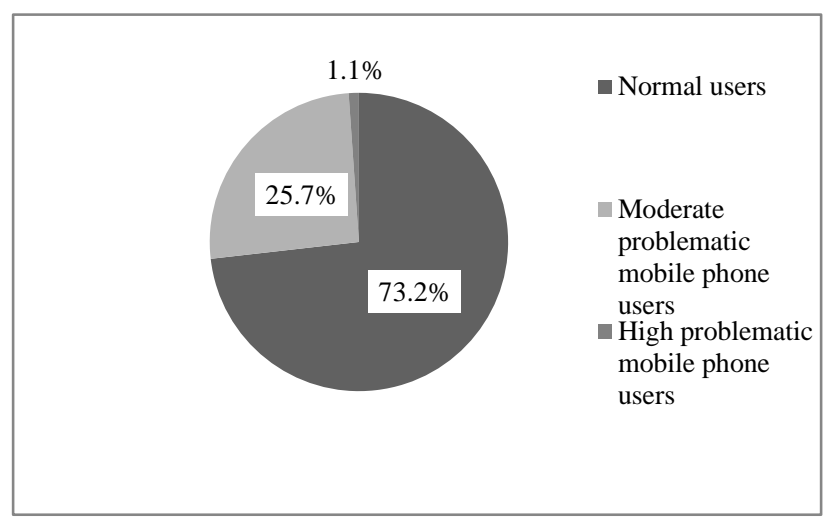

Figure 1: Prevalence of problematic mobile phone use among the participants.

\section{Association between PMU and predictor variables}

Bivariate analysis was done to identify sociodemographic and descriptive variables associated with PMU which is shown in Table 2. Table 3 shows bivariate analysis to identify mobile phone use variables associated with PMU. Psychological distress was significantly associated with PMU with an odds ratio of 4.43. Fourteen variables which were significant in the bivariate analysis were considered for multivariable logistic regression model.

The variables were: gender, relationship status, socioeconomic status, smart phone use, internet facility in mobile phone, duration of mobile phone use, number of chat applications used, frequency of mobile phone use, performance in academics, confidence for a bright future, relationship with mother and friends of same sex, psychological distress and self-esteem. Enter method was used for finding the associated variables after adjusting. Table 4 shows the significant variables in multivariable analysis.

\section{DISCUSSION}

A 16-item scale named Problematic mobile phone use scale was used to find the PMU among the college students. The PMUS exhibits a good level of internal consistency indicated by coefficient of Cronbach's alpha. PMUS also has good construct validity because overuse item in the scale is consistent with the frequency of mobile phone use and is significantly associated with PMU.

A multidimensional scale, problematic Mobile phone Use Questionnaire (PMPUQ) was a 30 item- four point likert scale which measured four different facets of problematic use as a) dangerous use b) prohibited use c) dependence symptoms and d) financial problems, it has a Cronbach's alpha of $0.89 .^{9}$ 
The Mobile Phone Use Survey- MPPUS a unifactorial scale by Bianchi et al was constructed as a 27 item- ten point likert scale which had Cronbach's alpha of $0.92 .^{21}$

Table 2: Bivariate analysis to identify socio-demographic and descriptive variables associated with PMU.

\begin{tabular}{|c|c|c|c|c|}
\hline Variables & Normal users n (\%) & Problematic users n (\%) & Crude OR (95\% CI) & p-value \\
\hline \multicolumn{5}{|l|}{ Gender $(n=1104)$} \\
\hline Male & $262(62.5)$ & $157(37.5)$ & 1 & \multirow[b]{2}{*}{$<0.001$} \\
\hline Female & $546(79.7)$ & $139(20.3)$ & $0.43(0.32-0.56)$ & \\
\hline \multicolumn{5}{|c|}{ Current Relationship status (n= 1104) } \\
\hline Single & $717(74.8)$ & $241(25.2)$ & 1 & \multirow{3}{*}{$\begin{array}{r}<0.001 \\
0.307\end{array}$} \\
\hline In a relationship & $73(57.9)$ & $53(42.1)$ & $2.16(1.47-3.17)$ & \\
\hline Married & $17(85)$ & $3(15.0)$ & $0.53(0.15-1.81)$ & \\
\hline \multicolumn{5}{|l|}{ Living arrangement } \\
\hline With parents & $714(74.1)$ & $250(25.9)$ & 1 & \multirow[b]{2}{*}{0.091} \\
\hline Other than parents & 97 (67.4) & $47(32.6)$ & $1.38(0.95-2.02)$ & \\
\hline \multicolumn{5}{|l|}{ Current student status } \\
\hline Full time student & $746(73.4)$ & $271(26.6)$ & 1 & \multirow[b]{2}{*}{0.691} \\
\hline Part time student & $65(71.4)$ & $26(28.6)$ & $1.10(0.68-1.77)$ & \\
\hline \multicolumn{5}{|c|}{ Socio-economic status $(n=1062)$} \\
\hline Class I, II and III & $581(70.7)$ & $241(29.3)$ & $1.85(1.29-2.65)$ & \multirow[b]{2}{*}{0.001} \\
\hline Class IV and V & $196(81.7)$ & $44(18.3)$ & 1 & \\
\hline \multicolumn{5}{|c|}{ Relationship with father } \\
\hline Positive & $698(73.9)$ & $247(26.1)$ & 1 & \multirow[b]{2}{*}{0.228} \\
\hline Negative & $113(69.3)$ & $50(30.7)$ & $1.25(0.87-1.80)$ & \\
\hline \multicolumn{4}{|c|}{ Relationship with mother (n=1107) } & \multirow[b]{3}{*}{0.004} \\
\hline Positive & $794(73.9)$ & $281(26.1)$ & 1 & \\
\hline Negative & $16(50.0)$ & $16(50.0)$ & $2.82(1.39-5.73)$ & \\
\hline \multicolumn{5}{|c|}{ Relationship with friends of same sex } \\
\hline Positive & $783(74.1)$ & $273(25.9)$ & 1 & \multirow[b]{2}{*}{0.002} \\
\hline Negative & $28(53.8)$ & $24(46.2)$ & $2.45(1.40-4.31)$ & \\
\hline \multicolumn{5}{|c|}{ Self-reported academic performance $(n=1106)$} \\
\hline Below average & $16(61.5)$ & $10(38.5)$ & $1.78(1.35-2.33)$ & \multirow{3}{*}{$\begin{array}{c}<0.001 \\
0.06\end{array}$} \\
\hline Average & $287(66.6)$ & $144(33.4)$ & $2.12(0.98-4.98)$ & \\
\hline Above average & $506(78.0)$ & $143(22.0)$ & 1 & \\
\hline \multicolumn{5}{|c|}{ Confidence for a bright future } \\
\hline Confident & 749 (74.5) & $257(25.5)$ & 1 & \multirow[b]{2}{*}{0.003} \\
\hline Not confident & $62(60.8)$ & $40(39.2)$ & $1.88(1.23-2.87)$ & \\
\hline \multicolumn{4}{|c|}{ Perception about body weight } & \multirow{3}{*}{0.078} \\
\hline Not satisfied & $260(69.9)$ & $112(30.1)$ & $1.28(0.97-1.69)$ & \\
\hline Satisfied & $551(74.9)$ & $185(25.1)$ & 1 & \\
\hline \multicolumn{5}{|c|}{ Participation in Sports and ECA $\uparrow+(n=1107)$} \\
\hline No & $345(76.3)$ & $107(23.7)$ & $0.77(0.58-1.01)$ & \multirow{2}{*}{0.056} \\
\hline Yes & $466(71.1)$ & $189(28.9)$ & 1 & \\
\hline Psychological distress & & & & \\
\hline Normal & $785(75.2)$ & $259(24.8)$ & 1 & \\
\hline Psychological distress & $26(40.6)$ & $38(59.4)$ & $4.43(2.64-7.44)$ & $<0.001$ \\
\hline Self esteem & & & & \\
\hline Low/ moderate & $82(56.2)$ & $64(43.8)$ & $2.44(1.71-3.50)$ & $<0001$ \\
\hline High & $729(75.8)$ & $233(24.2)$ & 1 & -0.001 \\
\hline
\end{tabular}

$\uparrow+$ ECA: Extracurricular activities 
Table 3: Bivariate analysis to identify mobile phone use variables associated with PMU.

\begin{tabular}{|c|c|c|c|c|}
\hline Variables & Normal Users n (\%) & Problematic users n (\%) & Crude OR (95\% CI) & p-value \\
\hline \multicolumn{5}{|c|}{ Smart phone use $(n=1101)$} \\
\hline No & $507(81.9)$ & $112(18.1)$ & 1 & \multirow{2}{*}{$<0.001$} \\
\hline Yes & $298(61.8)$ & $184(38.2)$ & $2.79(2.12-3.68)$ & \\
\hline \multicolumn{5}{|c|}{ Internet facility in mobile phone } \\
\hline No & $226(86.6)$ & $35(13.4)$ & 1 & \multirow[b]{2}{*}{$<0.001$} \\
\hline Yes & $585(69.1)$ & $262(30.9)$ & $2.89(1.97-4.25)$ & \\
\hline \multicolumn{5}{|l|}{ Using mobile phone for } \\
\hline Less than 3 years & $554(80.1)$ & $138(19.9)$ & 1 & \multirow[b]{2}{*}{$<0.001$} \\
\hline More than 3 years & $257(61.8)$ & $159(38.2)$ & $2.48(1.89-3.26)$ & \\
\hline \multicolumn{5}{|l|}{ Chatting apps used } \\
\hline None & $369(84.1)$ & $70(15.9)$ & 1 & \multirow{3}{*}{$\begin{array}{r}0.001 \\
<0.001\end{array}$} \\
\hline One chat app & $310(75.2)$ & $102(24.8)$ & $1.73(1.24-2.44)$ & \\
\hline Two or more chat apps & $132(51.4)$ & $125(48.6)$ & $4.99(3.51-7.11)$ & \\
\hline \multicolumn{5}{|c|}{ Frequency of mobile phone use (n=1105) } \\
\hline Low use & $199(88.4)$ & $26(11.6)$ & 1 & \multirow{3}{*}{$\begin{array}{r}0.050 \\
<0.001\end{array}$} \\
\hline Medium use & $125(81.2)$ & $29(18.6)$ & $1.78(1.00-3.15)$ & \\
\hline High use & $485(66.8)$ & $241(33.2)$ & $3.80(2.46-5.89)$ & \\
\hline
\end{tabular}

It covered the addiction aspect of mobile phone use such as tolerance, withdrawal, escape from problems, craving and negative consequences upon life. The PMUS used in this study is a uni-dimensional scale consisting of questions pertaining to dependence, dangerous use, overuse, sleep disturbances, ringxiety, compromised interpersonal relationships and behavioural problems related to mobile phone use. $26.8 \%$ of the participants in study sample were in the PMU category. Financial issues related to mobile phone bills were not considered in this research.

The relationship status of the participant was inquired because it was anticipated by the authors, those who are in a committed relation may use their phone in an uncontrolled manner. The current relationship status showed a significant association with problematic use of mobile phones. As compared to the singles category, in which $25.1 \%$ were problematic mobile phone users, the 'in a relationship/ committed category had $42.1 \%$ as problematic users.

The gender distribution in the study sample was nearly in the ratio of 2:3 for males to females. Males were more likely to be in the PMU category with gender as female, showing an odds ratio of 0.65 after adjusting. In a study by Toda et al, the authors discuss females express their emotions and prefer indirect communication more than males and the study by Martinez et al describes males adopt new technology faster than females. ${ }^{10,23}$

Majority of the studies done on problematic mobile phone use report females as the problematic gender, but in the present study, results were not consistent with the earlier findings. ${ }^{6,15,21-23}$ The explanation may be based on
$60 \%$ of the males having smartphones as compared to $33 \%$ of the females who had smartphones. The higher income category had increased odds of being in the PMU category by 1.85 times $(\mathrm{p}<0.001)$.

The problematic mobile phone behaviour in the higher socio-economic class may be explained by the fact that $86.7 \%$ of the smartphone users were in class I, II and III combined. The socio-economic status was not significant after adjusting while gender was associated to PMU. The latest generation of mobile phones, smart phones, allow its users to engage in a wide range of activities. The unadjusted odds of being a problematic user with using a smartphones were 2.79 times as compared to participants who did not use a smartphone $(\mathrm{p}<0.001)$. A study done by Lee et al in 2014 among adult sample showed that compulsive usage of smartphone and techno-stress were positively related to psychological traits with a $p$ value of $<0.001$. $^{24}$

Nearly one third of the participants $(31.7 \%)$ acquired a mobile phone during or before the age of 15 years with the mean age at beginning mobile phone use as 16.3 $( \pm 2.1)$ years. These findings clearly state that adolescents have access to mobile phones from early age.

Parents provide mobile phones to children because they want to be in contact, but in this age the mind is immature and probable misuse of technology may occur easily, therefore parent's supervision may be required at this age. $38.2 \%$ of mobile phone users for more than 3 years were in the PMU as compared to $19.9 \%$ less than 3 year users of mobile phone displaying PMU. In a study done by Bivin et al in 2013 among undergraduate students of life sciences college, it was found that $91.04 \%$ 
users were from the category using mobile phone for more than 3 years. $^{20}$ In this study patterns of mobile phone use were significantly associated with Nomophobia severity ( $p$ value $<0.001$ ). In the present study, year of study in college was not significantly associated with PMU. A study done by Dixit et al in 2010 showed that Nomophobia was highest among the $1^{\text {st }}$ year students in a medical college. ${ }^{19}$

Table 4: Multivariable logistic regression analysis using problematic mobile phone use as dependant variable.

\begin{tabular}{|c|c|c|}
\hline $\begin{array}{l}\text { Variables } \\
(\mathrm{n}=1062)\end{array}$ & $\begin{array}{l}\text { Adjusted OR } \\
(95 \% \text { CI })\end{array}$ & p-value \\
\hline \multicolumn{3}{|l|}{ Gender } \\
\hline Male & 1 & \multirow[b]{2}{*}{0.012} \\
\hline Female & $0.65(0.47-0.91)$ & \\
\hline \multicolumn{3}{|c|}{ Current relationship status } \\
\hline Single & 1 & \\
\hline In a relationship & $1.91(1.23-2.97)$ & 0.004 \\
\hline Married & $1.37(0.35-5.44)$ & 0.652 \\
\hline \multicolumn{3}{|l|}{ Smart phone use } \\
\hline No & 1 & \\
\hline Yes & $1.55(1.09-2.20)$ & 0.015 \\
\hline \multicolumn{3}{|c|}{ Number of chatting apps used } \\
\hline None & 1 & \multirow{3}{*}{$\begin{array}{l}0.898 \\
0.028\end{array}$} \\
\hline Single chat app & $0.97(0.60-1.57)$ & \\
\hline $\begin{array}{l}\text { Two or more chat } \\
\text { apps }\end{array}$ & $1.81(1.07-3.06)$ & \\
\hline \multicolumn{3}{|c|}{ Frequency of mobile phone use } \\
\hline Low & 1 & \multirow{3}{*}{$\begin{array}{r}0.028 \\
<0.001\end{array}$} \\
\hline Medium & $2.08(1.08-3.99)$ & \\
\hline High & $3.27(1.95-5.49)$ & \\
\hline \multicolumn{3}{|c|}{ Relationship with mother } \\
\hline Positive & 1 & \multirow[t]{2}{*}{0.044} \\
\hline Negative & $2.46(1.03-5.91)$ & \\
\hline \multicolumn{3}{|c|}{ Psychological distress } \\
\hline Normal & 1 & \multirow[t]{2}{*}{$<0.001$} \\
\hline Distress present & $3.25(1.68-6.31)$ & \\
\hline \multicolumn{3}{|l|}{ Self esteem } \\
\hline $\begin{array}{l}\text { Low or } \\
\text { moderate }\end{array}$ & $2.01(1.27-3.16)$ & \multirow[t]{2}{*}{0.003} \\
\hline High & 1 & \\
\hline
\end{tabular}

While $76.4 \%$ of the participants had internet facility in their mobile phone, $44.9 \%, 19.4 \%$ and $19.0 \%$ of the total participants independently used Whatsapp, Facebook messenger and We-chat applications respectively, which is consistent with the popularity of chat apps downloaded from the store.

The odds of being a problematic mobile phone user increase with increasing number of applications in the mobile phone. A study done by Carbonell et al among young students from 11-25 years in categories, showed that out of the total CERM (Cuestionario de Experiencias
Relacionadas con el Móvil) score, text messaging explained $12.5 \%$, internet $2.3 \%$ and chat applications $1.6 \%$ of the abusive use of mobile phones. ${ }^{15}$

Due to the categories being defined by a pre-decided cutoff from previous literature and continuous variable combined to form a categorical variable, the information about individual exposure of calls and messages was lost. $65.7 \%$ of the participants showed high frequency of mobile phone use which may not be an exact indicator of usage because there are several other uses of a mobile phone which were not considered.

High frequency use of mobile phones was closely associated with PMU. A study conducted by Thomée et al in Sweden in the year 2010 among young adults, found that $22 \%$ of the males and $24 \%$ of the females were in category high frequency use of mobile phones. ${ }^{12}$ The findings were very low which may be explained by the fact that in messaging category of present study, other messages were included along with SMS and messages through other chat apps.

The present study addressed the family and social relationships of participants in which unadjusted odds, for relationship with friends of same sex and mother, was statistically significant while other relations such as relationship with father, siblings, friends of opposite sex and relationship between mother and father were not significantly related with PMU.

Martinez et al conducted a study in Spain among adolescents, the relationship between parents was significantly related with intensive mobile phone use with a chi-square value of $6.74(\mathrm{p}<0.01){ }^{23}$ Also, in the same study, the relationship with family was significantly related with intensive mobile phone use i.e. mobile phone use more than 4 times a day or monthly bill of atleast $\$ 43 /$ month. Intensive cell phone use in the study was measured as $41.7 \%$ among the participants. ${ }^{23}$

A study done by Pillai et al in Goa among young population showed prevalence of psychological distress as $7.9 \%$ using GHQ ${ }^{25}$ In the present study, psychological distress was found to be $5.8 \%$ among the young adults attending college. The mean scores of GHQ were higher among the PMU category as $10.14( \pm 4.87)$ whereas the score among Normal users was $7.85( \pm 3.42)$. In a study done by Carbonell et al. among young students 18-25 years age group, using CERM Spanish for Problematic use of cellphone, it was found, $15.2 \%$ were in the Occasional Problematic category while $0.9 \%$ were in the Frequent problematic category. ${ }^{17}$

Around $44 \%$ of the lower self-esteem categories were problematic users as compared to $24.2 \%$ of the high selfesteem category experiencing PMU. In a study done by Yang et al in 2010 among Taiwanese adolescents, an OR of 2.46 ( $\mathrm{CI}=1.92-3.17)$ among girls and $2.38(\mathrm{CI}=1.63$ 3.45) among boys was found for relationship between 
problematic cellular phone and low self-esteem. ${ }^{13}$ The findings from present study were consistent with the results of Taiwan study.

One of the few research studies addressing problematic mobile phone use in India, the strengths of the study were the scientific selection of the sample and representation of students from the study area. A strict protocol was followed while data collection and participants were ensured confidentiality and anonymity so they were more likely to give truthful responses.

Although a significant association was present between PMU and psychological distress and self-esteem, the limitations of the research are temporality cannot be proved in a cross sectional study. Secondly, recall bias may have been present for number of messages and calls. Also, PMUS had good internal consistency but it was not validated against a standard questionnaire.

\section{CONCLUSION}

With this research, significant cross-sectional associations between problematic mobile phone use and psychological distress and self-esteem were supported. Factors such as smartphone use, a committed relationship, multiple chat applications and negative relationships around the participant increase the likelihood of being problematic mobile phone users. Further research needs to be done in the area of smartphone use, and adequate awareness should be generated among the youth and general population in relation to the rational use of technology and preventing it from overpowering lives and producing deleterious mental health effects or behavioural difficulties among individuals.

\section{ACKNOWLEDGEMENTS}

Authors would like to acknowledge all principals/ chairpersons of the colleges for giving permissions to conduct the study and participants for their active involvement and honest responses. Authors acknowledge the psychologists and psychiatrists who helped in validation of the tool. Authors would also like to thank the authors whose research on problematic mobile phone was a starting point for this study.

\section{Funding: No funding sources}

Conflict of interest: None declared

Ethical approval: The study was approved by Institutional Ethics Committee, Kasturba Medical College, Manipal, India

\section{REFERENCES}

1. Telecommunication $H$. History of Indian Telecommunication. Telecom Talk. 2011 [15 May 2014]. Available from: http://telecomtalk.info/ history-of-indian-telecommunication/67789.
2. Press release on telecom subscription data as on 31st March, 2014. 2014 May 12 [cited May 14]. Available from: http://www.trai.gov.in/ WriteReadData/ WhatsNew/ Documents/ Press\% 20Release- TSD-Mar,14.pdf

3. The mobile economy India 2013. 2014 [10 May 2014]. Available from: http://www. gsmamobileeconomyindia.com/ GSMA_ Mobile_ Economy_India_Report_2013.pdf

4. Roztocki N, Weistroffer H. Information and Communications Technology in Developing, Emerging and Transition Economies: An Assessment of Research. Papers.ssrn.com. 2009 [15 May 2014]. Available from: http://papers.ssrn.com/ sol3/ papers.cfm?abstract_id=1457435.

5. Bingi P, Leff LG, Shipchandler ZE, Rao S. Critical IT Implementation Issues in Developed and Developing Countries, Information Strategy. Exec J. 2000;16(2):25-34.

6. Augner C, Hacker GW. Associations between problematic mobile phone use and psychological parameters in young adults. Int $\mathbf{J}$ Public Health. 2012;57:437-41.

7. DSM-5 Coding Update Supplement to Diagnostic and Statistical Manual of Mental disorders, Fifth Edition. American Psychiatric Association March 2014 [cited May 7 2014]. Available from: http://dsm.psychiatryonline.org/ DocumentLibrary/ DSM-5\%20Coding\%20Update_Final.pdf

8. American Psychiatry Association. SubstanceRelated and Addictive Disorders. Available from: http://www.dsm5.org/Documents/Substance\%20Use \%20Disorder\%20Fact\%20Sheet.pdf

9. Billieux J. Problematic Use of the Mobile Phone: A Literature Review and a Pathways Model. Current Psychiatry Reviews. 2012;8.

10. Toda M, Monden K, Kubo K, Morimoto K. Mobile phone dependence and health-related lifestyle of University students in Japan. Social behavior and personality. 2006;34(10):1277-84.

11. Billieux J, Gay P, Rochat L, Linden M. The role of urgency and its underlying psychological mechanisms in problematic behaviours. Behaviour Research and Therapy. 2010;48:1085-96.

12. Thomée S, Härenstam A, Hagberg M. Mobile phone use and stress, sleep disturbances, and symptoms of depression among young adults - a prospective cohort study. BMC Pub Health. 2011;11(66):1-31.

13. Yang Y, Yen J, Hung C, Cheng C, Yen C. The association between problematic cellular phone use and risky behaviours and low self-esteem among Taiwanese adolescents. BMC Pub Health. 2010;10(217):1-8.

14. Yen CF, Tang TC, Yen JY, Lin HC, Huang CF, Liu $\mathrm{SC}$, et al. Symptoms of problematic cellular phone use, functional impairment and its association with depression among adolescents in Southern Taiwan. J Adolesc. 2009;32:863-73.

15. Sanchez-Carbonell X, Chamarro A, Griffiths $M$, Oberst U, Cladella R, Talarn A. Problematic 
Internet and cell phone use in Spanish teenagers and young students. Anales de psicología. 2012;28(3):789-96.

16. Leung L. Linking Psychological Attributes to Addiction and Improper Use of the Mobile Phone among Adolescents in Hong Kong. [cited 2013 Oct 15]. Available from: URL: http://www.tandfonline.com/ doi/ abs/ 10.1080/17482790802078565\#. U3Bx-vmSy8A

17. Carbonell X, Chamarro A, Griffiths M, Oberst U, Cladellas R, Talarn A. Problematic Internet and cell phone use in Spanish teenagers and young students. Anales de Psicología. 2012;28(3):789-96.

18. Hyun J, Chin B, Park D, Ryu S, Yu J. Characteristics of Excessive Cellular Phone Use in Korean Adolescents. Cyberpsychol Behaviour. 2008:11(6);783-4.

19. Dixit S, Shukla H, Bhagwat A, Bindal A, Goyal A, Zaidi A, et al. A Study to Evaluate Mobile Phone Dependence Among Students of a Medical College and Associated Hospital of Central India. Indian J Comm Med. 2010;35(2):339-41.

20. Bivin JB, Mathew P, Praveen C, Thulasi, Philip J. A cross sectional study on Nomophobia severity among male Under Graduate students of Health sciences. Reviews of Progress. 2013;1(1):1-5.

21. Bianchi A, Phillips JG. Psychological predictors of problem mobile phone use. Cyberpsychol Behav. 2005;8(1):39-51.

22. Takao M, Takahashi S, Kitamura M. Addictive Personality and Problematic Mobile Phone Use. Cyberpsychol Behav. 2009;12(5):501-7.
23. Martinez M, Otero A. Factors associated with cell phone use in adolescents in the community of Madrid (Spain). Cyber psychol Behav. 2009;12(2):131-7.

24. Lee Y, Chang C, Lin Y, Cheng Z. The dark side of smartphone usage: Psychological traits, compulsive behavior and technostress. Computers in Human Behavior. 2014;31:373-83.

25. Pillai A, Andrews T, Patel V. Violence, psychological distress and the risk of suicidal behaviour in young people in India. Int $\mathrm{J}$ Epidemiol. 2009;38:459-69.

26. Dudala S, Arlappa N. An Updated Prasad's Socio Economic Status Classification for 2013. Available from: http://www.ijrdh.com/ files/ 1\%20Prasad\% 20SES.pdf

27. 12 item General Health Questionnaire [Internet] 2013 [15 Oct 2013]. Available from: http://www.workhealth.org/ UCI\%202007/ practicum\%2008\%20GHQ\% 202007.pdf

28. Rosenberg's self-esteem scale [Internet] 2013 [12 Oct 2013] Available from: http://www.yorku.ca/ rokada/ psyctest /rosenbrg.pdf.

Cite this article as: Pundir P, Andrews T, Binu VS, Kamath R. Association of problematic mobile phone use with psychological distress and self-esteem among college students in South India: a crosssectional study. Int J Community Med Public Health 2016;3:2841-9. 